\title{
Depression Scale
}

National Cancer Institute

\section{Source}

National Cancer Institute. Depression Scale. NCI Thesaurus. Code C121277.

A rating scale included in the Behavior Assessment System for Children that measures the tendency of the subject to have feelings of unhappiness, sadness, and stress that may result in an inability to carry out everyday activities. 